INTERNATIONAL DESIGN CONFERENCE - DESIGN 2018

https://doi.org/10.21278/idc.2018.0240

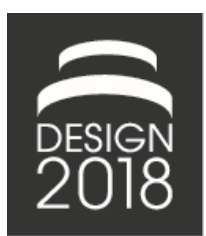

\title{
VALUE CREATION MECHANISMS IN PRODUCT VARIETY DEVELOPMENT
}

\author{
J. T. Pakkanen, T. S. Juuti and T. A. Lehtonen
}

\begin{abstract}
The aim is to study value creation mechanisms in product variety development and to discuss how the mechanisms could be used in communicating and evaluating the business potential of product variety development. The mechanisms were recognised by studying the literature of modularisation, product platform and product family development. Mechanisms that increase and decrease profit were found. Industrial case study suggests that clarifying the important value creation mechanisms can be beneficial in negotiating the justification to invest in R\&D projects in supporting the business.
\end{abstract}

Keywords: product variety, decision making, modularisation, product families, portfolio management

\section{Introduction}

This paper is about studying value creation mechanisms (VCM's) in product variety development. VCM's present the business objectives that could be considered by applying certain tactics of product variety development. In this paper value creation includes value creation for a business of a company and value creation for a customer. Product variety describes the range of products the company can offer within a certain period of time in response to market demand (Ulrich and Eppinger, 2008).

The purpose of studying VCM's is to highlight the possibilities of product development in improving business cases of companies. Also, reviewing these mechanisms is important because as, for example, Howard et al. (2008) and Gericke and Blessing (2011) have explained, the aim of the design processes, methodologies and approaches is to facilitate the remembering of the essential issues in designing in addition to other benefits.

We are also interested about the co-creation and improving communication and understanding between different organisations including engineering, management and business control to make it easier to argument and evaluate the potential of engineering concepts and to make it easier to justify or decline the need for research and development (R\&D) investment. Explicitly defined VCM's could be used as a guidance in finding beneficial structure for a product variety that considers also commonality and design reuse aspects. Also, recognising the generic and relevant mechanisms in product variety development could support the development of analysis tools for estimating what kind of business potential could be achieved if certain mechanisms could be realised successfully.

Markets expect products that satisfy customer needs. This is the situation also in the manufacturing industry. Many of the companies are facing the challenge of increased product variety. Product variety enables potential for increased market shares, but typically costs more than offering a standard product. If the existing product variety does not fulfil the business goals, it needs to be revisited. Modularisation, product platform and product family development are often suggested product development tactics to 
work as a support in enabling product variety, but also managing costs by considering potential of design reuse and commonality (Jiao et al., 2007).

Modularisation aims for defining modular architecture and interfaces that supports interchangeability and independence of a set of modules that are building blocks of product variety. Modularisation should be aimed at reducing complexity in the company's operations and harvesting benefits in areas where the positive effects can be seen (Andreasen, 2011). Consequently, it is important to recognise the areas where the benefits could be achieved.

Creating a product platform and a product family have similar goals. A platform is a collection of core assets that are reused to achieve a competitive advantage (Kristjansson et al., 2004). The development of a product platform requires $R \& D$ experiences and enables creating product variants that are based on a certain reusable platform elements (Ulrich and Eppinger, 2008). Similar definitions have been presented by Lehtonen et al. (2003) stating that a product platform enables launching a product family that consists of modules and corresponds to certain market needs now and in predictable future.

As this brief definition of product development tactics for product variety development already discussed, it is important to clarify in which areas potential exists and it would be helpful if there would exist support for estimating the overall business potential or effects already during early phases of product development. This is because product design is a critical phase in determining for example manufacturing and other life cycle costs (Ulrich and Pearson, 1993).

Many of the design processes and design methodologies consider target setting and evaluating the design. Typically, design processes and methods start with setting requirements and goals. Creating a requirement list (Pahl and Beitz, 2013) is a classic example of the early steps in a design process. During and after designing, solution candidates are typically evaluated against goals that were set in the beginning of product development project. Pahl and Beitz (2013) and Ulrich and Eppinger (2008) suggest evaluating designs against technical and economic criteria. These generic and well-known approaches do not underline very extensively product variety development that also considers design reuse and commonality aspects based on modularisation, product platform development and product family development. Because of this and the motivation discussed in the beginning of introduction, this paper focuses on reviewing VCM's of the above-mentioned tactics of product variety development and to discuss how the mechanisms could be used in communicating and evaluating the business potential of the product variety development in the manufacturing industry. Thus, we aim to seek answer to following research questions (RQ's) by reviewing the literature and studying an industrial case:

- RQ1. What are the main value creation mechanisms (VCM's) in product variety development in the manufacturing industry?

- RQ2. Which of the VCM's were relevant in the case study?

Research strategy for RQ1 is a survey focusing on literature review whereas RQ2 benefits from the case study. Section 2 begins with defining the generic life steps of the manufacturing industry and continues with the literature review on VCM's in product variety development. Literature review was conducted using mainly the Design Society, Google Scholar and Scopus databases. Those are covering many potential sources in this research field sufficiently. The search focused on journal articles, books, book chapters and conference papers related to product variety development. Number of different search terms and their combinations related to product variety development were used. Hundreds of results were returned based on the search limited on titles. Titles of papers, abstracts, results cited by highest number were studied to find out the relevant publications to be studied in greater detail. Because of high number of publications, there is a potential risk that this paper is missing references that are valid in this context. In the summary of Section 2, we connect the mechanisms to the generic life steps of the manufacturing industry and briefly discuss about the findings from the literature. Section 3 presents an example of considering VCM's in the case study in the manufacturing industry. Finally, discussion and conclusions are given in Sections 4 and 5.

\section{Value creation mechanisms in product variety development}

This section starts with presenting the main life phases of the manufacturing industry. After this, a literature review is conducted in order to recognise relevant VCM's in the field. Finally, a brief summary is presented. 


\subsection{Generic life steps of the manufacturing industry}

To make Section 2.2 easier to follow, we discuss about the generic process steps of the manufacturing industry first. These steps are used in our review to link VCM's on. As discussed in the introduction, incremental redesigning or new product development is typically needed if product variety does not fulfil business goals and the cost of offering product variety is too high. Product development can be done in different levels. As an example, company can develop completely new product, families of products, features or it can do redesigning focusing on updating or correcting designs, change commercial components or update technologies. Product development is followed by marketing and sales. From the perspective of product variety development, marketing and sales must possess enough technical support and knowledge related to product variety. In many cases, sales configurator is used to support marketing and sales (Haug et al., 2012). The result of successful marketing and sales is a description of delivery content. Production can include procurement of components and materials, subcontracting, manufacturing, testing of parts and modules, assembly and final testing of the product variant. Transport is also important aspect when considering product variety development because companies may have different logistic concepts based on their customers. Products might require installation or implementation in the customer or operating site until the product is ready for use. Use is followed by service and finally, revision, retirement or recycling takes place. To summarise, the following steps can be recognised in the manufacturing industry:

- Product development

- Marketing and sales

- Production

○ Procurement of component and material

- Subcontracting

- Manufacturing

- Testing (parts, assemblies, modules)

- Assembly

- Final testing (product variant)

- Transport

- Installation and implementation

- Use

- Maintenance and end-of-life phases (revision, retirement, recycling)

\subsection{Literature review on the value creation mechanisms in product variety development}

This section aims to review generic VCM's discussed in the literature of product variety development based on modularisation, product platform development and product family development. In the end of each topic, a bulleted summary about the main mechanisms is presented based on the studied literature.

Baldwin and Clark (2000) explain that modular design needs investments because of formulating design rules, experimenting, designing modules and testing. Consequently, R\&D investment is one of the major mechanisms that needs to be considered in product variety development. Thus, a VCM linked to product development can be defined.

- Product development: Research and development investment

Duffy and Ferns (1999), Pulkkinen (2007) and Juuti (2008) state that design reuse reduces the needed engineering effort per product delivery. Cost, quality and time effects are mentioned. According to Erixon (1998) and Juuti (2008), reusing parts, sub-systems or a product are some of the possible drivers for modularisation to reduce design effort. Sanchez (1999) explains that reusing component designs reduces the development costs of new product variants. Interfaces are also important design element in product variety development. Standardised interfaces facilitate reusing and planned design changes (Erixon, 1998; Fujimoto, 2007). Hence, design reuse is important mechanism in product variety development and it can be done in different levels. We summarised these arguments in two VCM's related mainly to product development. 
- Product development: More capacity for new product development

- Product development: Design by reuse (component, interface, module or solution)

Considering technology aspects in product variety development is important. Technological evolution or technology push can set requirements for those products whose technology develops fast (Erixon, 1998). For example, Harlou (2006) considers future product elements in defining a product family architecture. Encapsulated technologies are discussed in the modularisation context. It is said that isolating design parameters clearly from the other parts of the design makes incorporation of new solutions easier (Baldwin and Clark, 2000). Lehtonen et al. (2003) state that encapsulation of modules reduces complexity in product management. Thus, following VCM's are also relevant to product development.

- Product development: New technologies

- Product development: Encapsulated technologies

Designing product variety based on different product development tactics affects to the product cost. Andreasen et al. (1996) explain that variety can create additional costs to several life phases unless commonality of the products is not considered. Sanchez (1999) state that use of common components in product variety may reduce product costs. Fixson (2006) discusses that part count reduction is a typical cost reduction tool. This leads us to defining a VCM that is part of marketing and sales.

- Marketing and sales: Product cost

There exists limited research on studying relations between the use of certain product development tactic and customer behaviour. Hopp and $\mathrm{Xu}(2005)$ discuss about brand effect being one factor in analysing the demand for offering variants based on modularity. Tiihonen et al. (1998) explain that enabling configurable products contributes to brand management issues. This is very case specific mechanism. We have seen case studies in which the use of word "modular" was forbidden because of unsuccessful modularisation projects that did not enable customer value despite the use of this word as a marketing argument. These references highlight another VCM that relates to marketing and sales.

- Marketing and sales: Brand impact

Designing a modular product family based on certain platform can require large investments and may not be done very often in large scale within a company. Harlou (2006) discusses that in designing a modular product family, attractiveness of the products also in the future is decided. Erixon (1998) discusses that consideration of styling possibilities can be important driver for modularisation in the products whose purchasing decision trends and fashion strongly affects. That is to say, companies have to consider if their products include elements that are vulnerable to quickly changing expectations, standards or legislation by the market or society and if these changes can be reacted effectively. Pulkkinen (2007) and Juuti (2008) add that modularisation supports fitting of product to customer needs by product configuration which is about defining a product variant based on predefined rules and product elements. Based on these explanations, following VCM's are connected to marketing and sales.

- Marketing and sales: Reactivity to market changes

- Marketing and sales: Fit product to customer needs, standards and local legislation

Support for sales about possibilities of product variety is significant to capture the benefits related on the predesigned elements such as modules and interfaces. Product configuration knowledge has been discussed by several authors as a facilitator of sales, distributing tendering and product variant definition. Soininen (2000) explains that configuration model improves product configuration process. Human or software driven configurator facilitates defining of individualised products (Victor and Boynton, 1998). Haug et al. (2012) have recognised benefits of using IT-based configurators such as shorter lead time, increased quality of specifications, preservation of knowledge, need for fewer resources for specifying the product and reduced time needed for training people. A VCM supported by these references is part of marketing and sales.

- Marketing and sales: Support for sales and distributing tendering or product variant definition 
Delivery specific products are more challenging than standard products for production because of possible unfamiliar structures and thus benefits of learning and repetitions are more difficult to capture.

According to Sanchez (1999), designing modular components improves the predictability of product creation process (production). Baldwin and Clark (2000) discuss that modularity can be used to simplify complex processes in production. A VCM related to production was defined based on these arguments.

- Production: Improving controllability of production by transparency and predictability

Effective part procurement is important for companies. Large number of optional supply sources facilitates economical procurement. Baldwin and Clark (2000) discuss that if all items in a product line use common parts, economies in parts sourcing may exceedingly reduce the total cost of production. Therefore, we state that considering availability and number of supply sources are important in product variety development. This VCM is related to production.

- Production: Component availability and number of supply sources

Late point product differentiation by allocating variations to only one or few parts and keeping the product generic as long as possible lower the buffer inventories in production and thus reduce the complexity of manufacturing process and the overall costs (Lee and Tang, 1997; Erixon, 1998). Same topic has been studied by Sanchez (1999). He discusses about "universal chassis" including all the common components of product variety enable mass production benefits. Use of universal chassis may reduce variety of parts that must be inventoried and handled in assembly according to Sanchez. He also explains that the late point differentiation may also reduce the costs of distributing product variety. These aspects lead to a VCM of production.

- Production: Late point differentiation

According to Lehtonen (2007), existing assembly and operating environment reasons of the product can favour production in the factory. He gives an example of submarine production during World War 2. Modularisation can enable production in the factory (prefabrication) instead in the site of the customer or in the operating environment of the product because of clearly defined building blocks. These statements highlight another VCM related to production.

- Production: Relocating production to more favourable area or environment

Erixon (1998) studied that separate testing of modules decreases feedback times about the quality of modules compared to testing done in the main production flow. Interfaces are important design element in modularisation (Pakkanen et al., 2016). Interfaces consider the limitations of an environment in which a module should be and can be used in without modifications. Thus, it is possible to develop separate testing equipment for each module. Based on these explanations, we define a VCM of production:

- Production: Decreased ramp up time and costs with distributed module testing

Reuse of components may increase the reliability of key components over the time because reuse enables incremental improvements and learning in materials and processes (Sanchez, 1999; Juuti, 2008). Juuti states that this reduces warranty costs. Therefore, this VCM can be linked with production.

- Production: Reduction in component quality issues

Well-specified interfaces in modular products enable distributed assembly and, for example, product modules can be delivered to a customer in which the product is assembled effectively (Lau et al., 2007). Possibility to decentralise assembly can be important for instance because of limitations of existing facilities or remoteness of market areas. Obviously, this VCM is related to main life phase of production.

- Production: Distributing or decentralising assembly

We already discussed about component quality issues, but the whole product quality is also important aspect. In product variety development, one should find proven solutions if design reuse by predesigned module structures and product platform is aimed for. According to Tiihonen et al. (1998), product configuration which is enabled by modularisation relates to managing product quality because product configuration focuses on defining product variant based on only certain predefined rules and limitations. 
According to Juuti (2008), fully configurable product is made of standardised (at least within a company) and therefore, the risk for mistakes is minimised. Based on these definitions another VCM related to production can be defined.

- Production: Reduction in product quality issue

Products can be designed to match the chosen type of logistics. Fixson (2006) explains that product architectural decisions determine the needed packing space and protection requirements of the product that have relation to logistic costs including transportation. Erixon (1998) presents that standardised modules enable lower administration costs of logistics because of the lower number of assortment. These considerations of logistics bring us to defining VCM related to life phase of transport.

- Transport: Decreased cost of transportation

Regarding life phase of installation and implementation, reduction in component and product quality issues were already discussed. These are very relevant also in installation and implementation.

Modularity in use enables customer to reorganise the elements of the final product to match their new taste or needs (Baldwin and Clark, 2000). Baldwin and Clark explain that reconfiguring can be made by substitutions, augmentations or exclusions. Accessibility and type of interfaces have strong effect regarding this mechanism. Based on this, a VCM related to use is defined.

- Use: Enabling reconfiguring of product during use

Integrated products are typically more difficult to maintenance than products which apply modular structures and standardised interfaces. Modularisation can be done by focusing on the easiness of replacing the possible damageable areas (Erixon, 1998). Umeda et al. (2000) discuss about the maintenance-oriented modularisation. They state that companies should focus in recognising the similar life times of components and designing the product in a way that replacement of working components would be avoided always when possible if maintenance is needed in other components. Also, they discuss that proper designing can help to create new business for companies in the later life phases by providing for example services for reducing the amount of waste by reusing the modules. Finally, VCM's related to maintenance and later life phases can be summarised.

- Maintenance and end-of-life phases (revision, retirement, recycling): Reduced down time and maintenance cost by replaceable modules

- Maintenance and end-of-life phases (revision, retirement, recycling): Increased end-of-life value by reusing modules

\subsection{Summary}

Figure 1 summarises findings from the literature and is the main contribution to RQ1. Figure 1 also presents what is considered in this paper and what is part of future research. Potential for future studies is discussed later in Sections 4 and 5. The left-hand side describes generic life steps of the manufacturing industry from product development to recycling. VCM's have been presented in the right-hand side. Customer specific aspects are emphasised in the list of recognised mechanisms, but also many product development and production aspects have been recognised. These mechanisms describe possible objectives, phenomena and problems that product variety development based on modularisation, product platform development and product family development can influence.

The figure presents only the most relevant relations between the life steps and VCM's, but mechanisms might have relations also to other life steps.

In addition to VCM's based on the literature, we also added increased or decreased number of sales as a mechanism related to marketing and sales. We have seen industrial product development projects in which changes in the number of sales have been a reason for starting a rationalisation project of product variety to either make the product more interesting in the market or make it more effective to offer based on the increased demand. 


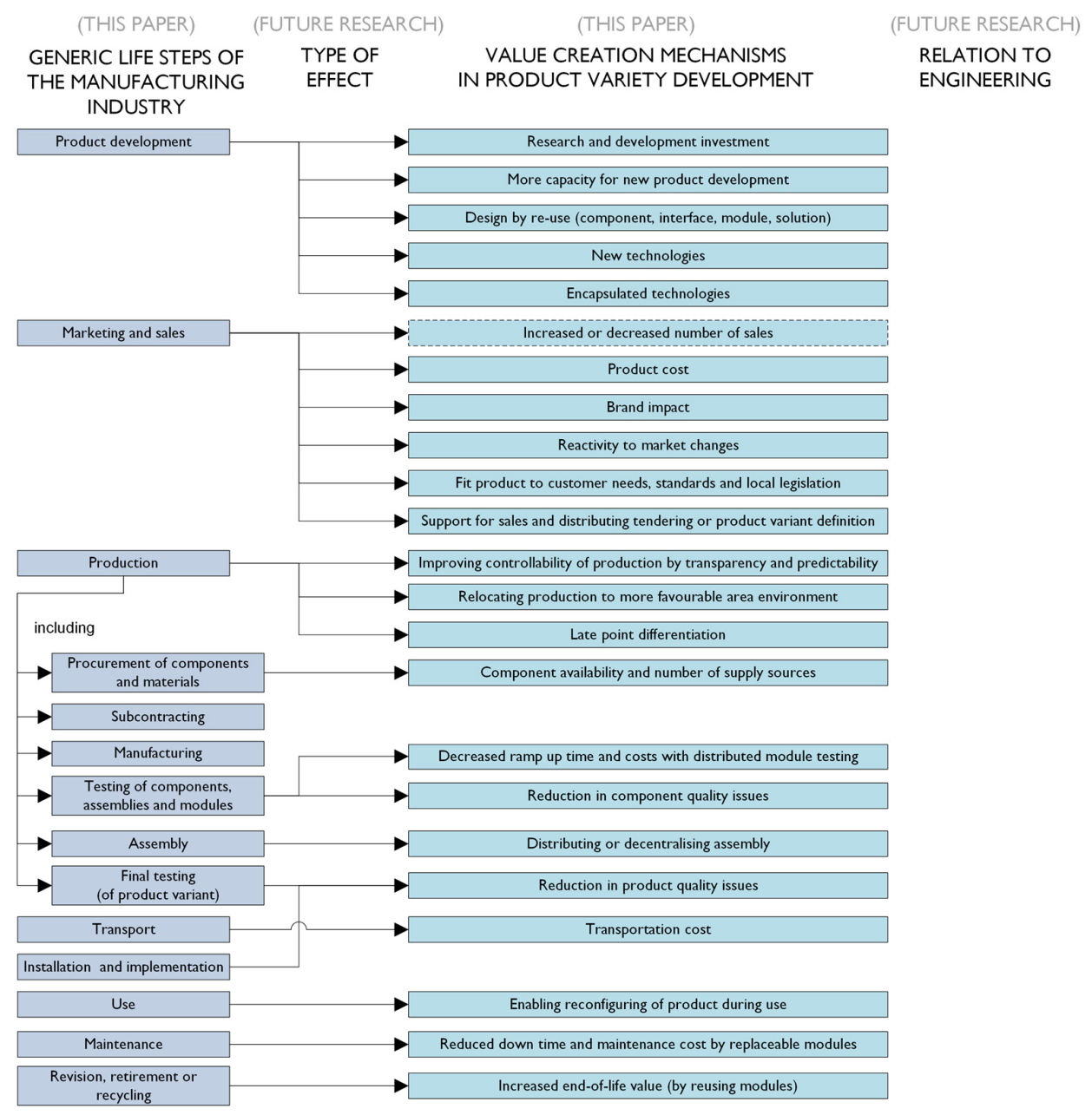

Figure 1. The value creation mechanisms (VCM's) of product variety development in the manufacturing industry

\section{Case study in machinery industry}

The main support needed for answering RQ2 of "Which of the VCM's are relevant in the case study?" is described in this section. Answering this question is based on a retrospective case study. The case study was conducted in the machinery industry in a company that requires product variety to satisfy the market need. Company manufactures manufacturing equipment for global markets. The starting point in the company was diversified product variety and the impression of expensive product life cycle management. Therefore, the company started a rationalisation project of product variety. Going through the rationalisation project during 2009-2011 has been presented in greater detail by Pakkanen (2015) and Pakkanen et al. (2016). The final outcomes of the original case study are already known when data collection for this paper took place. Two authors of this paper observed and participated in the original case study and the analysis made for this paper is based on their notes. Authors had access to archival data collected when the significant events explained in earlier publications occurred. In this paper, we retrospectively study the same industrial project with a focus on recognising if VCM's derived from the literature differ from our findings from industry. The main focus is on two phases: target setting done in the beginning of the project and business impact analysis done in the end of the project. We start with discussing how target setting proceeded in the company using condensed narrative structure and define which of the VCM's presented in Figure 1 can be considered as valid in this case study based on what the company personnel discussed. Because the case study is not completely anonymous (earlier publications), only percentages are used when discussing about quantitative values to protect the real case. 
As discussed, the original objective was to decrease the resource need for upkeeping the products. After estimating the potential business impact of rationalising the product life cycle management, it was found out that this would be about $10 \%$ of the R\&D budget. Experts in the company made all the estimations about the potential effects based on their knowledge and availability of financial data. From the perspective of the business environment this was minor effect because the share of R\&D was only few percent of the whole business. Thus, only focusing on the cost of product life cycle management was considered insufficient. Thereafter, it was considered where the development effort should be focused on to improve the situation more.

At first, reducing the costs related to R\&D mechanisms was thought. It was estimated that by investing to $R \& D$ and enabling design by reuse in different levels, the original objective of decreasing the cost of product life cycle management can be achieved while recognising also potential for the other benefits. At this phase, following VCM's could be considered relevant.

- Product development: Research and development investment

- Product development: More capacity for new product development

- Product development: Design by reuse (component, interface, module or solution)

- Product development: New technologies

- Marketing and sales: Support for sales and distributing tendering or product variant definition

Other potential benefits discussed in the company included lower costs of production by different mechanisms and higher value of the product for the customer. The analysis of potential was promising compared to the original estimation of $10 \%$ potential of the R\&D budget. The company estimated that by investing to $R \& D$ the overall potential is larger than the whole proportion of $R \& D$ with acceptable time of repayment. Therefore, we can retrospectively define that the following VCM's presented in Figure 1 were recognisable in this phase of target setting.

- Production: Improving controllability of production by transparency and predictability

- Production: Late point differentiation

- Marketing and sales: Reactivity to market changes

- Maintenance and end-of-life phases (revision, retirement, recycling): Reduced down time and maintenance cost by replaceable modules

- Maintenance and end-of-life phases (revision, retirement, recycling): Increased end-of-life value by reusing modules

The company focused on increasing commonality within the product variety by following design tactics of modularisation, product platform and product family development and product configuration. This required a lot of redesigning, but the work was justified after estimating the business impacts. Because of redesigning and implementing the rationalised product variety successfully, operational costs were reduced even $40 \%$ in certain cost topics while the average expectations were from 15 to $20 \%$ and product costs of some variants decreased $25 \%$ in total. Therefore, we present one more VCM that was not mentioned earlier as valid in this case study.

- Marketing and sales: Product cost

When considering the list of VCM's presented in Figure 1 and answer to RQ2, all of the VCM's were not relevant in this case study, but the study supports the defined list of VCM's based on what was discussed in the company.

\section{Discussion}

If we are able to define a generic list of VCM's, it would be interesting to study how applying this list would affect to goal setting and evaluating business impacts of product development compared to a situation where this kind of generic support is unavailable. At this point regarding future studies, one could make a hypothesis that it would be more effective to find arguments for the need of R\&D investment to be presented to managers making the final decision using a design support that facilitates connecting and discussing the potential of product development and value creation mechanisms explicitly in affecting the whole business. This case study was not able to prove this potential hypothesis correct but it facilitated finding new topics to be studied in the future. 
Recognising VCM's support development of more systematic tools for estimating business impacts of product variety development. We did not present quantitative or qualitative measures for each VCM's. These are relevant aspects of future research. One starting point for this direction could be consideration of general measurable quantities that Olesen (1992) names as universal virtues including cost, throughput time, quality, efficiency, flexibility, risk and environment.

Results of this paper differ with other studies in this context such as product architecture costing by Fixson (2006) or more generic House of Quality (HoQ) by Hauser and Clausing (1988). Fixson aims to model the mechanisms between product architecture characteristics of function-component allocation and interfaces and the costs and time in different life phases. Thus, the approach by Fixson (2006) includes quantitative measures but we think that the dimensions from the engineering viewpoint could be more extensive in product variety development. Figure 1 suggested considering relation of VCM's to engineering as part of future research. One potential option to present the product design and engineering viewpoint instead of considering only function-component allocation and interfaces could include using the elements of module system in this area including set of modules, interfaces, architecture, configuration knowledge and partitioning logic as presented by Pakkanen et al. (2016). Compared to HoQ, the approach presented in this paper is more business oriented instead of customer oriented. The basic HoQ highlights considering relations between customer perspective and engineering characteristics. This leads us to another potential topic for future studies of how generic design processes consider VCM's. It is important that in addition to fulfilling customer requirements, products have to create value for business, not only customer value.

\section{Conclusions}

Benefits of different product development tactics are often discussed in design publications but the actual mechanisms enabling those benefits are more uncommonly reviewed in the literature. We studied articles related to product variety development and recognised number of generic VCM's and connected these to the life phases from product development to recycling.

We suggest that in the beginning of a development project the organisation should define the main goal and go through the VCM's and define which of the mechanisms support the goal and focus on those mechanisms. The presented VCM's can be used as a support for understanding, communicating and estimating potential business impacts of product variety development. The VCM's present profit increasing and decreasing mechanisms. Investments to R\&D are necessary if potential is seen with new or updated product variety. The presented model is not a systematic tool for this purpose but a starting point for this direction. The content of the model needs to be connected to quantitative values to increase the usefulness for management perspective and more detailed link from VCM's to engineering is also required to support possibilities of product design activities to affect the important VCM's in each case.

\section{References}

Andreasen, M.M. (2011), “45 Years with design methodology”, Journal of Engineering Design, Vol. 22 No. 5, pp. 293-332. https://doi.org/10.1080/09544828.2010.538040

Andreasen, M.M., Hansen, C.T. and Mortensen, N.H. (1996), "The Structuring of Products and Product Programmes", Proceedings of the 2nd WDK Workshop on Product Structuring, Delft, The Netherlands, June 34, 1996, pp. 15-44.

Baldwin, C.Y. and Clark, K.B. (2000), Design Rules: The Power of Modularity, The MIT Press, Cambridge.

Duffy, A.H.B. and Ferns, A.F. (1999), “An analysis of design reuse benefits”, Proceedings of ICED'99/the $12^{\text {th }}$ International Conference on Engineering Design, Munich, Germany, The Design Society, pp. 799-804.

Erixon, G. (1998), Modular Function Deployment - A Method for Product Modularisation, PhD thesis, The Royal Institute of Technology, Stockholm, Sweden.

Fixson, S.K. (2006), “A Roadmap for Product Architecture Costing”, In: Simpson, T.W., Siddique, Z. and Jiao, R.J. (Eds.), Product Platform and Product Family Design, Springer, Boston, MA, pp. 305-334. https://doi.org/10.1007/0-387-29197-0_13

Fujimoto, T. (2007), Competing to Be Really, Really Good - The behind-the-Scenes Drama of Capability Building Competition in the Automobile Industry, International House of Japan, Tokyo.

Gericke, K. and Blessing, L. (2011), "Comparisons of design methodologies and process models across domains: a literature review”, Proceedings of ICED'11 / the 18th International Conference on Engineering Design, Vol. 1, Copenhagen, Denmark, August 15-18, 2011, The Design Society, pp. 393-404. 
Harlou, U. (2006), Developing Product Families Based on Architectures - Contribution to a Theory of Product Families, PhD thesis, Technical University of Denmark.

Haug, A., Hvam, L. and Mortensen, N.H. (2012), "Definition and evaluation of product configurator development strategies”, Computers in Industry, Vol. 63 No. 5, pp. 471-481. https://doi.org/10.1016/j.compind.2012.02.001

Hauser, J.R. and Clausing, D. (1988), "The House of Quality", Harward Business Review, Vol. 66 No. 3, pp. 63-73.

Hopp, W.J. and Xu, X. (2005), "Product Line Selection and Pricing with Modularity in Design", Manufacturing \& Service Operations Management, Vol. 7 No. 3, pp. 172-187. https://doi.org/10.1287/msom.1050.0077

Howard, T.J., Culley, S.J. and Dekoninck, E. (2008), "Describing the creative design process by the integration of engineering design and cognitive psychology literature", Design Studies, Vol. 29 No. 2, pp. 160-180. https://doi.org/10.1016/j.destud.2008.01.001

Jiao, J., Simpson, T.W. and Siddique, Z. (2007), "Product family design and platform-based product development: A state-of-the-art review", Journal of Intelligent Manufacturing, Vol. 18 No. 1, pp. 5-29. https://doi.org/10.1007/s10845-007-0003-2

Juuti, T. (2008), Design Management of Products with Variability and Commonality - Contribution to the Design Science by Elaborating the Fit Needed between Product Structure, Design Process, Design Goals, and Design Organisation for Improved R\&D Efficiency, PhD thesis, Tampere University of Technology, Tampere.

Kristjansson, A.H., Jensen, T. and Hildre, H.P. (2004), "The term platform in the context of a product developing company", Proceedings of DESIGN 2004 / the 8th International Design Conference, Dubrovnik, Croatia, May 17 - 20, 2004, The Design Society, Glasgow, pp. 325-330.

Lau, A.K.W., Yam, R.C.M. and Tang, E. (2007), "The impacts of product modularity on competitive capabilities and performance: An empirical study”, International Journal of Production Economics, Vol. 105 No. 1, pp. 1-20. https://doi.org/10.1016/j.ijpe.2006.02.002

Lee, H.L. and Tang, C.S. (1997), "Modelling the Costs and Benefits of Delayed Product Differentiation", Management Science, Vol. 43 No. 1, pp. 40-53. https://doi.org/10.1287/mnsc.43.1.40

Lehtonen, T. (2007), Designing Modular Product Architecture in the New Product Development, PhD thesis, Tampere University of Technology, Tampere.

Lehtonen, T., Juuti, T., Pulkkinen, A. and Riitahuhta, A. (2003), "Dynamic Modularisation - A challenge for design process and product architecture", Proceedings of ICED'03 / the 14th International Conference on Engineering Design, Stockholm, Sweden, August 19-21, 2003, The Design Society, Glasgow.

Olesen, J. (1992), Concurrent Development in Manufacturing - Based on Dispositional Mechanisms, Institute for Engineering Design, $\mathrm{PhD}$ thesis, The Technical University of Denmark.

Pahl, G. and Beitz, W. (2013), Engineering Design: A Systematic Approach, Springer Science \& Business Media.

Pakkanen, J. (2015), Brownfield Process: A Method for the Rationalisation of Existing Product Variety towards a Modular Product Family, PhD thesis, Tampere University of Technology.

Pakkanen, J., Juuti, T. and Lehtonen, T. (2016), "Brownfield Process: A method for modular product family development aiming for product configuration", Design Studies, Vol. 45, pp. 210-241. https://doi.org/10.1016/j.destud.2016.04.004

Pulkkinen, A. (2007), Product Configuration in Projecting Company: The Meeting of Configurable Product Families and Sales-Delivery Process, PhD thesis, Tampere University of Technology.

Sanchez, R. (1999), "Modular Architectures in the Marketing Process", Journal of Marketing, Vol. 63, pp. 92-111. https://doi.org/10.2307/1252104

Soininen, T. (2000), An Approach to Knowledge Representation and Reasoning for Product Configuration Tasks, $\mathrm{PhD}$ thesis, Helsinki University of Technology, Espoo.

Tiihonen, J., Lehtonen, T., Soininen, T., Pulkkinen, A., Sulonen, R. and Riitahuhta, A. (1998), "Modelling configurable product families", Proceedings of ICED'99 / the $12^{\text {th }}$ International Conference on Engineering Design, Munich, Germany, August 24-26, 1999, The Design Society, pp. 1139-1142.

Ulrich, K.T. and Eppinger, S.D. (2008), Product Design and Development, McGraw-Hill, New York.

Ulrich, K.T. and Pearson, S.A. (1993), Does Product Design Really Determine 80\% of Manufacturing Cost?, Alfred P. Sloan School of Management, Cambridge, Massachusetts.

Umeda, Y., Nonomura, A. and Tomiyama, T. (2000), "Study on life-cycle design for the post mass production paradigm”, Artificial Intelligence for Engineering Design, Analysis and Manufacturing, Vol. 14 No. 2, pp. 149161. https://doi.org/10.1017/S0890060400142040

Victor, B. and Boynton, A.C. (1998), Invented Here: Maximizing Your Organization's Internal Growth and Profitability, Harvard Business School Press, Boston, Massachusetts.

Dr. Jarkko Tapani Pakkanen, Postdoctoral Researcher

Tampere University of Technology, Mechanical Engineering and Industrial Systems

PO Box 527, FI-33101 Tampere, Finland

Email: jarkko.pakkanen@tut.fi 